\title{
The Time Delay to Start Evacuation: Review of Five Case Studies
}

\author{
GUYLÈNE PROULX \\ National Fire Laboratory \\ Institute for Research in Construction \\ National Research Council of Canada \\ Ottawa, Canada, K1A 0R6 \\ RITA F. FAHY \\ Fire Analysis and Research Division \\ National Fire Protection Association \\ Quincy, MA 02269-9101, USA
}

\begin{abstract}
Models to predict occupant response and evacuation will be an essential part of the move throughout the world toward performance-based codes and standards, as they are necessary for calculating the time required for occupants to reach safety, given a proposed design. To obtain realistic evacuation time predictions, it is essential to be able to accurately calculate the delay times occupants take before beginning evacuation.

This paper reviews the findings from five evacuation studies. These studies include evacuation drills in midrise and highrise apartment buildings and midrise office buildings. Findings from two fire incidents - a six-fatality highrise apartment building fire in Canada and the World Trade Center bombing in New York City - are also discussed. The findings of particular interest are those related to problems in alerting occupants, delays reported or observed during evacuations, and the reasons behind those delays.
\end{abstract}

KEYWORDS: human behaviour, evacuation times, delay times, midrise buildings, highrise buildings.

\section{INTRODUCTION}

Performance-based codes and standards are being developed and adopted around the world in order to allow more flexibility in design, which in turn is expected to reduce the cost of building construction. A variety of computer models and calculation tools will be used to evaluate the level of safety provided by an engineered design. Occupant evacuation models will be an essential component in this process, since the time required for occupants to reach safety is an essential component of ensuring safety.

Some evacuation models are already available $[1,2,3]$. While most models can usually reproduce the space geometry (i.e., length and width of corridors and stairs), variables related to the occupants themselves are often ignored. Evacuation models need to do more than 
simply predict the travel times for the occupants as they move to safety. In order to accurately calculate the total time to evacuate a building, components such as the notification time and the occupants' pre-movement time must be taken into account. A frequent assumption of evacuation models is that occupants will start their evacuation at the time of the fire alarm sounding. Even though this assumption is basically wrong, since there normally is a time delay between occupants perceiving the alarm and starting to evacuate, many evacuation models do not compute any delay time before starting. To be able to confidently rely on evacuation models as tools for fire safety decision making, it is essential that evacuation models reflect reality as closely as possible. Consequently, it is essential to include a reasonable delay for occupants to start their evacuation in all evacuation models. Some models, such as EXIT89 and FiRECAM ${ }^{\mathrm{TM}}[1,4]$ have the capacity to include a delay time in calculating the overall evacuation time. The time delays used in these models are currently user inputs, based on best judgment, due to the lack of data on delay times to start evacuation.

The development of evacuation models and their subsequent use by designers and code officials require considerable understanding of what happens to people in a fire situation, including how occupants will be notified, how much time will elapse before they begin their evacuation, what they might encounter as they move through the building and how they will react to those events or obstacles, as well as how long it will take them to travel the necessary distance.

To facilitate the development and use of such evacuation models, data from evacuation drills and case studies are needed. Currently, model users and alarm system designers make assumptions about how an alarm system will operate and how people will react in real emergencies. Data from evacuation drills and case studies can also be used to test those assumptions. The current evacuation models treat delay times differently; some calculate delay times after notification while others require that they be specified by the user. In all cases, fire safety engineered designs require data on reaction time, pre-movement time and behaviour during evacuation. This data is obtained from evacuation drills and case studies.

This paper will summarize the findings related to the time to start evacuation from five case studies. Two projects involved evacuation drills in midrise and highrise apartment buildings and one involved evacuation drills in midrise office buildings. The other two projects studied human behaviour during actual fires - one in a highrise apartment building that killed six occupants and the other in a mega-structure, the World Trade Center in New York City.

\section{FIVE CASE STUDIES}

To gather information on the time to start, case studies on human behaviour during evacuations were conducted. The results presented should not be generalized to all buildings. The delay times determined in the case studies are indicators of the range one may expect to experience in a given fire event. It was observed that the delay to start varied in relation with the type of occupancy, the occupants' characteristics and the fire safety features in the buildings.

\section{Apartment Building Drills}

Two projects involved a series of evacuation drills conducted in 1993-1995. The studies collected data on time and movement during evacuation drills in midrise and highrise apartment buildings $[5,6]$. Midrise buildings are structures less than $36 \mathrm{~m}$ in height with more than 3 storeys which require a passenger elevator. Highrise buildings are structures over $36 \mathrm{~m}$ in height as defined by the National Building Code of Canada 1995. The apartment buildings studied were four midrises, 6 or 7 storeys high with an average of 

300 occupants.

The same methodology was used for all seven buildings. The occupants received a memo that an evacuation drill would take place in the coming week without giving the exact day and time. During each drill, data was collected through the use of over 30 videocameras. The cameras recorded such events as the time to leave an apartment, occupant movement in corridors and staircases, and occupant behaviour throughout the evacuation. The data collected from these videotapes was recorded in a transcript and statistical analyses were performed.

The local fire department participated in all drills according to a predetermined fire scenario. The fire was always assumed to be on the fifth floor and a pre-designated occupant was instructed to activate the alarm on that floor after receiving a call from the principal researcher. Firefighters arrived 4-6 minutes later in full gear with their trucks' sirens on. They performed their duties according to their normal procedures for such buildings; locating the origin of the fire alarm and ensuring that all occupants had evacuated the building. At this point, the captain gave the 'all clear' signal and occupants were permitted to return to their apartments.

After each evacuation drill, a questionnaire was distributed. Occupants were asked questions regarding actions they took after hearing the alarm, their evacuation route, and their general , level of knowledge about fire safety procedures within the building.

\section{Office Building Drills}

The same methodology was used in conducting two office evacuation drills in 1995. The difference between the apartment and the office drills was that the office drills were unannounced; no memo was distributed to occupants. The two office buildings studied were heritage buildings 6 to 7 storeys high. One office building had 180 occupants with a total floor area of $7544 \mathrm{~m}^{2}$ and the other had over 500 occupants with a total floor area of $18500 \mathrm{~m}^{2}$. Both buildings had a mix of open plan and enclosed offices. The drills took place on weekday afternoons between 14:00 and 14:15, in order to have the largest possible number of occupants in the buildings [7].

\section{Fire in an Apartment Building}

The Forest Laneway Fire occurred on January 6, 1995. The fire originated from a carelessly discarded cigarette on a couch in an apartment on the 5th floor of a 30 -storey apartment building. When the fire started, at approximately 5:00 a.m., most of the 550 occupants of the building were asleep. The tenant in the apartment of fire origin attempted, unsuccessfully, to extinguish the fire. Neighbours were alerted by the smoke and one operated a manual pull station. The tenant from the apartment of fire origin left his unit, leaving both the living room patio-door to the balcony and the main apartment door to the corridor open. The door of the apartment of fire origin was located directly across the corridor from a door to one of the two exit staircases. The intense flames damaged the door to the staircase, letting smoke and hot gases penetrate the staircase enclosure. Occupants on other floors were alerted by the smoke or the fire alarm and many tried to evacuate using the stairs. The repeated opening of apartment and exit staircase doors on different floors contributed to the rapid spread of smoke throughout the building. Six casualties were later found in the two staircases, victims of smoke inhalation. A study of the occupants' behaviour during the fire was undertaken with the intent of gathering data on human behaviour during this tragedy. The information was collected using a questionnaire mailed to occupants of every unit in the building [8]. 


\section{Fire in a Mega-Structure}

The World Trade Center in New York City was the site of a bomb blast in February 1993. The explosion and subsequent fire caused extensive structural damage on several basement levels. The incident also damaged the fire protection and other emergency system and resulted in the evacuation of approximately 100,000 occupants from the two 110 -storey towers and a 22-storey hotel. Six people were killed in the explosion and over 1,000 people were injured.

To obtain data on the dynamics of human behaviour during the incident and to document details of the building and fire, a questionnaire was developed and sent to the tenants of the towers. The results show the initial perception of the seriousness of the situation among occupants and how they became aware that something was happening. During the evacuation, most respondents moved through the building in total darkness and a majority moved through smoke. It took from 30 minutes to 3 hours to leave the building. A majority of the respondents had never participated in or practised, the evacuation procedures for the building [9].

\section{DELAYS TO START EVACUATION}

The case studies show a large variation in delays to start evacuation for the different buildings. It is important to emphasize that a straight comparison of these times is not appropriate. It should be noted that the times to start in the fire cases were the subjective assessments of occupants answering a questionnaire, while in the drills, these times were precisely measured with videocameras. It is worthwhile, however, to examine and contrast these cases to establish similarities and differences that could have broader application.

\section{Average Time to Start During Fire Drills}

The case studies of the midrise and highrise apartment buildings and the office midrise buildings were evacuation drills. In the residential occupancies, the time to start is the mean time occupants took to leave their apartments as presented in Table 1. It is not possible to know the exact number of occupants present in the buildings at the time of each evacuation drill; nevertheless, since the firefighters knocked on all doors to notify the occupants to leave, it is safe to assume that most occupants who were present in the building participated in the evacuation drill.

\section{TABLE 1. Average Time to Start During Residential Evacuation drills}

\begin{tabular}{|c|c|c|}
\hline Building & Midrise & Highrise \\
\hline 1 & $2: 30$ & $2: 48$ \\
\hline 2 & $8: 22$ & $5: 19$ \\
\hline 3 & $9: 42$ & \multicolumn{1}{|}{} \\
\hline 4 & $3: 08$ & \multicolumn{1}{|c|}{} \\
\cline { 1 - 2 } & &
\end{tabular}

The time to start during residential evacuation drills varied significantly among buildings. The main factor to explain these differences was the subjective assessment of the occupants' ability to hear the fire alarm in each building. In the post-evacuation questionnaire, occupants had to judge if they felt that, in their apartments, the fire alarm was not loud enough, loud enough or too loud. For buildings where at least $80 \%$ of the occupants mentioned that the alarm was loud enough or too loud, it was judged that the building had a "good alarm" system, otherwise the alarm was judged a "poor alarm". Midrise Buildings 1 
and 4, with a good alarm, had a combined average time to start of 2:49. Conversely, the two other Midrise Buildings 2 and 3, with a poor alarm, had a combined average time to start of $8: 35$. In the residential buildings with a poor alarm, occupants started their evacuation when they were warned by arriving fire truck sirens or firefighters knocking at their apartment doors. Data for one of the highrise buildings could not be considered in this analysis since the alarm system malfunctioned; the two other highrises were considered to have a "good alarm". The average times to start, however, are significantly different with $2: 48$ and $5: 19$. The explanation for this difference is that the second highrise drill occurred during a snowfall and occupants had to get dressed before leaving their apartments.

To substantiate these subjective assessments of the occupants regarding the alarm, specific measurements were performed in some buildings. The results show that, in all the buildings studied, even if more than $80 \%$ of the occupants judged the alarm as loud enough, there were always some rooms in apartments where the alarm did not meet audibility requirements. In other areas of the same buildings, such as corridors and staircases, the alarm was overpowering [10].

Occupants were asked in the post-evacuation questionnaires what their activities were after they heard the alarm. After being notified by perceiving the alarm, being told or hearing the fire truck sirens, the most commonly mentioned pre-movement activities were; "have a look in corridor", "gather valuables", "get dressed", "find children", "find pets" and "move to balcony" [11].

The time to start in evacuation drills in the two office buildings was the time at which occupants either crossed the door of their offices, stepped outside their area dividing panels or left their desks in open concept areas. The average times to start, which were precisely recorded by videocameras, were 0:36 and 1:03, respectively. The time delay was used for pre-movement activities such as gathering valuables, getting dressed and notifying others. The two office buildings had alarm systems judged loud enough or too loud, by $95 \%$ and $98 \%$ of occupants. As presented in Figure 1, the time delay to start was much shorter in the office drills compared to the residential drills. The good alarm audibility, the occupant training and the presence of fire wardens to prompt the evacuation are variables that explain the difference in time delays between office and residential drills.

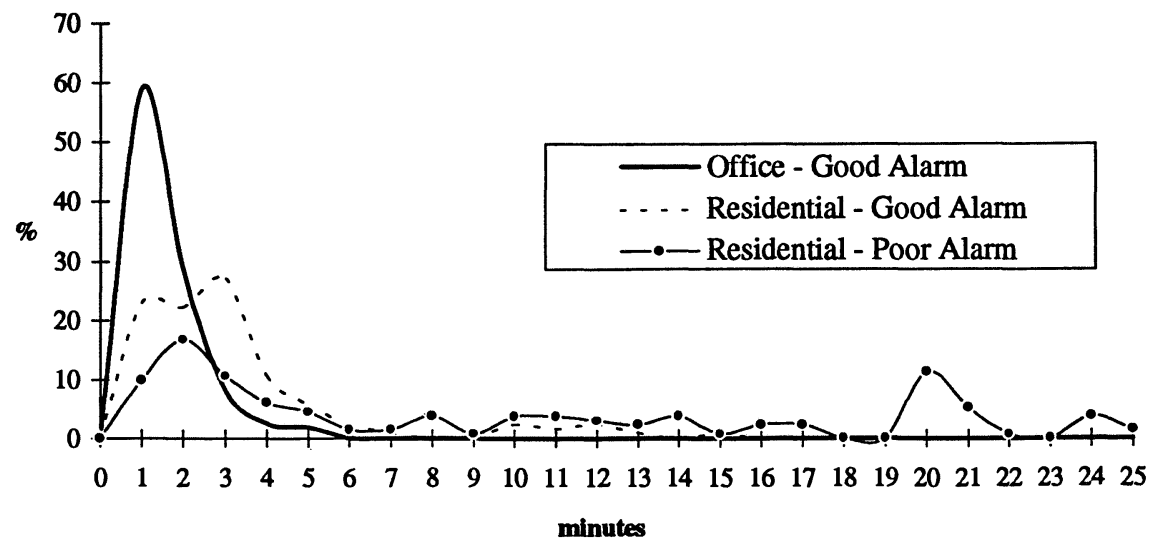

\section{FIGURE 1. Delay to Start during Residential and Office Drills}

In all drills (residential and office), an average of 20 to $25 \%$ of the occupants mentioned in their questionnaires that, upon hearing the fire alarm, they thought it might be a real fire emergency. 


\section{Average Time to Start During Two Fires}

It is reasonable to expect that a comparison of evacuation drills and actual fires would show differences. Some may expect that, in a real fire, occupants would start more quickly due to fire cues, such as smoke, and a feeling of threat. In fact, the time delay before starting to evacuate is often longer during actual fires compared to drills due to the uncertainty of the situation and the ambiguity of the cues perceived by the occupants, both of which characterize most fires in large buildings $[12,13]$.

The average time to start in the Forest Laneway Fire, as determined from an occupant survey, should be examined with care. Respondents who complete a questionnaire a few days or, as in this case, 2-3 weeks after the incident, have a marked tendency to round off times. In this case, most respondents gave time measures that were multiples of five and many gave answers to the closest half hour. The time reported should not, therefore, be used to determine events within seconds. These times are, nevertheless, interesting because they provide a good time range and help create the chronology of the events.

From the questionnaires on the Forest Laneway Fire, many occupants started their evacuation at around 10:00 a.m., five hours after the fire started. This long delay can be explained by the fact that a majority of occupants evacuated the building only under the direction of rescue personnel, once the situation was under control. Even though close to half the occupants (48\%) attempted to evacuate in the first hour of the fire, $65 \%$ of them were unsuccessful in their evacuation attempt and had to seek refuge in other apartments or return to their own apartments. Many merely looked in the corridor and decided it was safer to stay in their apartments and wait to be rescued. As many as $24 \%$ of the respondents mentioned not hearing the fire alarm while inside their apartments. These occupants usually became aware of the fire by being told by others or by perceiving the smoke. The time data that is most interesting is the time of initial awareness that something unusual was going on and the time to attempt evacuation during the first half hour of the fire, as shown in Figure 2. Considering that the fire started at 5:00 a.m., occupants who became aware of the situation before 5:15 a.m. and attempted to evacuate before 5:30 a.m. were significantly more likely to reach ground level. None of the occupants above the fire floor, who started evacuating after 5:30 a.m., managed to reach ground level. The occupants who attempted to evacuate during the first hour had an average time to start of 10:31 after becoming aware of the situation. Overall, occupants took between 0 and 12 hours to start. The mean time occupants took to start evacuating was 3.18 hours after becoming aware of the situation with a median of 3.13 hours.

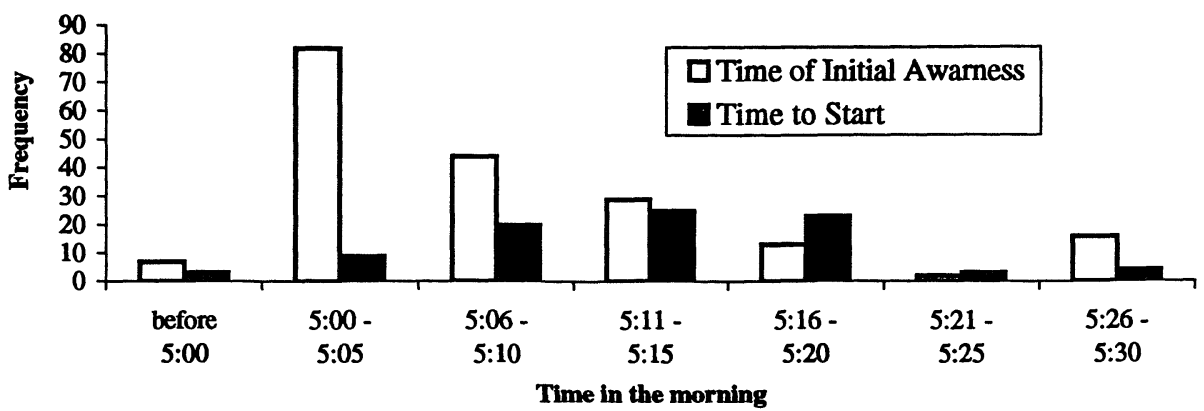

FIGURE 2. Time of Initial Awareness and Time to Start for the First 30 min

The emergency training of the occupants in the twin towers of the World Trade Center was such that, after the sound of the alarm, occupants had to wait on their floors for instructions. It was planned that these instructions would be given through the P.A. system. The 
emergency control centre delivering instructions as well as the fire alarm system, both located on a basement level, were destroyed by the explosion. The fire alarm did not sound and no message was given out through the P.A. system; occupants in the towers had to decide for themselves what to do after becoming aware of the incident.

An analysis of how occupants first became aware that something unusual was happening and then how they realized that what was happening was a fire or explosion resulted in a significant difference between the responses from the two highrise towers. Since the bomb was placed closer to Tower 1 than Tower 2, it was not surprising that cues were less ambiguous to Tower 1 respondents, and conditions in that building were somewhat worse.

For Tower 1, the reported time from awareness of fire or explosion to leaving ranged from 0 to 4.08 hours with a mean time of 11:02 and a median time of 5:00, as shown in Figure 3.

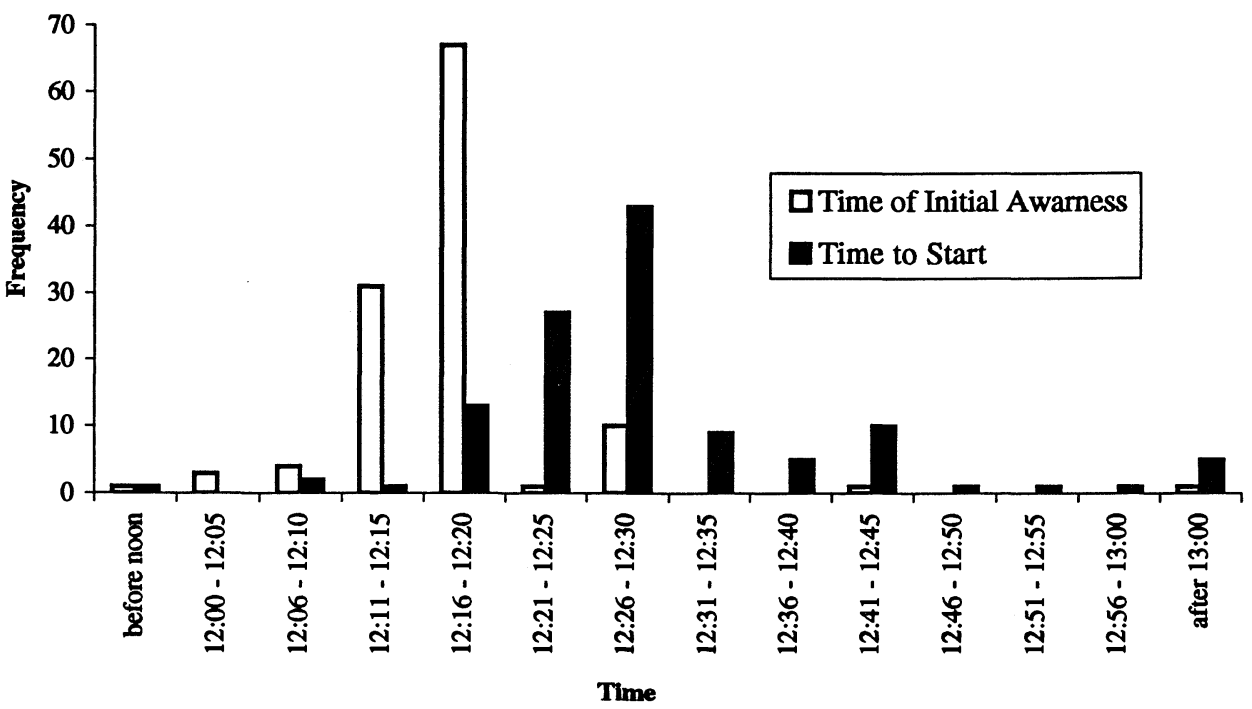

FIGURE 3. Time of Initial Awareness and Time to Start in Tower 1 
For Tower 2, the times ranged from 0 to 3.08 hours with a mean time of 25:24 and a median of 10:00, as shown in Figure 4. The time difference between the two towers was statistically significant.

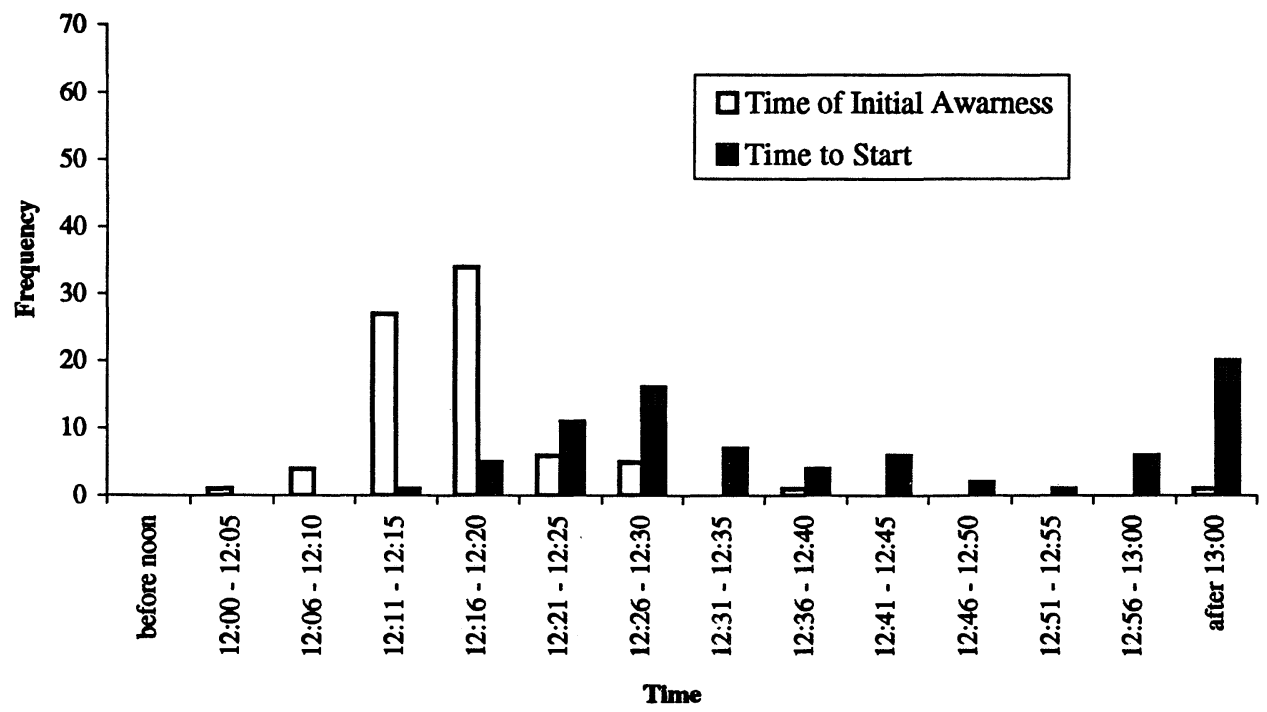

FIGURE 4. Time of Initial Awareness and Time to Start in Tower 2

\section{ANALYSIS OF DRILL AND FIRE STUDIES}

A summary of the average times to start in the five case studies is presented in Table 2. The times to start evacuation in the two fires are notably longer than in the drills. For the drills, the average times to start in residential buildings with good alarms are consistent with 2:49 except for the winter evacuation that had a longer time delay of 5:19 due to the fact that occupants had to get dressed before leaving. The residential buildings with poor alarms had a long average delay to start of 8:35. The office building drills had a shorter delay to start evacuation. One of the two buildings showed a significantly longer time to start, probably due to the cool weather which motivated many occupants to get their coats before leaving.

The two fire case studies have longer times to start. The time presented in Table 2 for the Forest Laneway Fire (FLF) is the overall time to start after occupants became aware of the situation, which is 3.18 hours. This very long time to start is related to the fact that many occupants learned about the fire a long time after the starting time and a majority decided to stay in their apartments and wait to be rescued. For the World Trade Center case study (WTC), the average time to start for occupants in Tower 1 was 11:02 after becoming aware of the situation and 25:24 in Tower 2. 
TABLE 2. Average Times to Start in the 5 Case Studies (min:s)

\begin{tabular}{|l|l|c|c||c|c|c|}
\cline { 2 - 6 } \multicolumn{1}{c|}{} & \multicolumn{3}{c||}{ DRILLS } & \multicolumn{3}{c|}{ FIRES } \\
\cline { 2 - 7 } \multicolumn{1}{c|}{$\begin{array}{c}\text { Residential } \\
\text { Midrise }\end{array}$} & $\begin{array}{c}\text { Residential } \\
\text { Highrise }\end{array}$ & $\begin{array}{c}\text { Office } \\
\text { Midrise }\end{array}$ & FLF & $\begin{array}{c}\text { WTC } \\
\text { Tower 1 }\end{array}$ & $\begin{array}{c}\text { WTC } \\
\text { Tower 2 }\end{array}$ \\
\hline Good alarm & $2: 49$ & $\begin{array}{l}2: 48 \\
5: 19 \text { Winter }\end{array}$ & $\begin{array}{l}0: 36 \\
1: 03 \text { Cool }\end{array}$ & & & \\
\hline Poor alarm & $8: 35$ & & & $198: 00$ & $11: 02$ & $25: 24$ \\
\hline
\end{tabular}

\section{TIME TO START IN RESIDENTIAL AND OFFICE OCCUPANCIES}

A number of variables that had an impact on the time delay to start in these case studies were identified. Some major differences were observed between the residential and the office occupancies as shown in Table 3.

TABLE 3. Main Variables Influencing the Time Delay to Start in the Case Studies

\begin{tabular}{|l|l|l|}
\hline \multicolumn{1}{|c|}{ Variables } & \multicolumn{1}{c|}{ Residential } & \multicolumn{1}{c|}{ Office } \\
\hline 1- Alarm audibility & Variable & Good \\
\hline 2-Interpretation of the situation & Ambiguous & Clear enough \\
\hline 3- Visual access & Poor & Good \\
\hline 4- Responsible for others & Yes & No \\
\hline 5- Preparedness & Active or Passive & Active \\
\hline 6- Pre-movement Activities & Long & Short \\
\hline 7- Training & Poor & Good \\
\hline 8- Fire Warden & No & Yes \\
\hline
\end{tabular}

During the drills, it was observed that good alarm audibility made a great difference in reducing the delay to start. In the two apartment buildings where the alarm was judged poor, occupants took significantly longer times to start their evacuations. The two fire case studies showed a similar situation. The absence of the sound of the alarm in the WTC likely delayed the time of awareness in Tower 2 which was less affected by the explosion and fire. Several occupants of the FLF mentioned not hearing the fire alarm from inside their apartments. The occupants who did not perceive the alarm learned about the fire later than other occupants. In learning later about the situation, they had significantly less chance of starting their evacuation early and of being successful in attempting to reach ground level. Apartment buildings with alarm sounders in the common corridors usually have a few apartments, or rooms within some apartments, where the sound of the alarm is not audible. Further, the sound of a majority of fire alarms has its main spectral components in the high frequencies over $3000 \mathrm{~Hz}$. High frequency alarms have difficulty penetrating materials such as walls and doors. Also, high frequency signals can be missed by people suffering from hearing loss, such as older people. This problem of alarm audibility was not observed in the office case studies. The large open spaces, low partition walls and the habit of keeping office doors open allowed all office occupants to hear the alarm immediately.

The openness in office space design compared to residential design accounts for some other differences. For instance, the interpretation of the situation is made easier in the office environment because it is possible to rapidly observe others and interact with colleagues about the situation. In residential occupancies, the situation is often ambiguous and difficult to define because occupants are limited in their opportunities to communicate with others. The spatial organization of office environments also allows for visual access giving an 
overview of the activities of others while residential buildings offer limited views which may increase the time delay to interpret the situation.

A major difference between the two occupancies is that, in office buildings, occupants are usually not responsible for others. All occupants are capable adults, so each person has to essentially take care of him or herself. The situation is entirely different in residential buildings. A long time will be spent gathering family members before starting to evacuate together and time may also be invested in looking for friends and neighbours who may need assistance.

In office buildings, occupants are awake, dressed and active; thus, they will need a shorter time to prepare to evacuate. Longer times will be needed to prepare in residential buildings since a large portion of the time spent at home is for sleeping and other resting activities, reading, watching $\mathrm{TV}$, taking a bath, etc. Consequently, the time to perform pre-movement activities, such as getting dressed, finding children or gathering valuables, will take longer in residential occupancies.

The amount of training received is another variable that differentiates residential from office buildings. There are wide variations in the extent of training offered in different office buildings. In North America, most office environments have emergency procedures that are usually practised by some or all occupants at least once each year. Residents' training in apartment buildings is not mandatory, so information sessions and evacuation drills are rarely performed. In general, residential occupants receive no organized training of the emergency procedures for the building in which they live.

Office buildings often have Fire Wardens who have received specific training. The Fire Wardens are responsible for prompting the evacuation and directing occupants of a floor or an area of a floor. There is no similar system in residential buildings to motivate occupants to respond quickly.

The average time delay to start in the residential drills with a good alarm accounted for two thirds of the overall evacuation time in the midrise and highrise buildings. The average time delay in office drills was just over one third of the evacuation time. Consequently, it appears that the time to start is a significant part of the evacuation no matter what distance occupants need to travel to reach safety.

\section{CONCLUSION}

Even though it has been observed that the sound of an alarm by itself is not informative of the occurrence of a fire situation and that people tend to ignore or deny this signal [14], it is still a useful way to alert occupants. Occupants may not start evacuating immediately upon hearing the alarm but, once they hear it, most will investigate to determine the reason for the alarm activation. The case studies show that an alarm with good audibility significantly reduced the time delay to start an evacuation. Further information about the situation is also needed by occupants to help them make their decisions to evacuate, as observed in the two fire case studies.

It is important to reiterate, however, that the times determined from the case studies should not be taken at face value as the "correct" times to use in evacuation models for residential and office occupancies. The time delays presented are essentially indications of the variation in time delays that have been observed in five North American case studies. More data must be gathered to generalize the results for specific design purposes. More evacuation drills are needed to define the difference in time delays between occupancies which result from specific variables, such as the audibility of the alarm, the use of P.A. messages and winter and summer evacuation. It is also important to continue studying fire incidents to identify pre-movement activities in relation to occupants' understanding of the situation. 
Overall, the time delay to start an evacuation was the longest during the residential drills. This time delay was notably reduced in the office environment due to such factors as training, preparedness, fire wardens and the absence of responsibility for others.

These five case studies show that the time delay to start an evacuation varies according to occupancies, fire safety features and occupant characteristics. The time delay to start can represent a large part of the total evacuation time. It is an essential component that must be included by model developers, designers and code officials to accurately calculate the overall evacuation time.

\section{REFERENCES}

1. Fahy, R. F., "EXIT89 - An Evacuation Model for High-Rise Buildings - Recent Enhancements and Example Applications", Proceedings of the International Conference on Fire Research and Engineering, D.P. Lund (Ed.), Society of Fire Protection Engineers, Boston, MA, USA, pp. 332-337, 1995.

2. Galea, E. R., Owen, M. and Lawrence, P. J., "Emergency Egress from Large Buildings under Fire Conditions Simulated Using the Exodus Evacuation Model", Proceedings of the Seventh International Fire Science and Engineering Conference, Interflam 96', InterScience Communications, London UK, pp. 711-720, 1996.

3. Poon, L. and Beck, V., "Numerical Modelling of Human Behaviour During Egress in Multi-Storey Building Fires Using EvacSim - Some Validation Studies", Proceedings of Asiaflam 95', InterScience Communications, London, UK, pp. 163-174, 1995.

4. Yung, D., Hadjisophocleous, G. V., Proulx, G. and Kyle, B. R., "The Use of NRC's FiRECAM for Retrofit of Office Buildings", Proceedings of the SFPE Symposium on Computer Application in Fire Protection Engineering (in press), June 20-21, 1996, Worcester MA, USA, 6 p, 1996.

5. Proulx, G., "Evacuation Time and Movement in Apartment Buildings", Fire Safety Journal, 24, 229-246, 1995.

6. Proulx, G., Latour, J.C., MacLaurin, J.W., Pineau, J., Hoffman, L.E. and Laroche, C., "Housing Evacuation of Mixed Abilities Occupants in Highrise Buildings", Internal Report IRC-IR 706, Institute for Research in Construction, National, Research Council Canada, Ottawa, Canada, 92 p, 1995.

7. Proulx, G., Kaufman, A. and Pineau, J., "Evacuation Time and Movement in Office Buildings", Internal Report IRC-IR 711, Institute for Research in Construction, National, Research Council Canada, Ottawa, Canada, 51 p, 1996.

8. Proulx, G., Pineau, J., Latour, J.C. and Stewart, L., "Study of the Occupants' Behaviour During the 2 Forest Laneway Fire in North York, Ontario on January 6, 1995", Internal Report IRC-IR-705, Institute for Research in Construction, National, Research Council Canada, Ottawa, Canada, 74 p, 1995.

9. Fahy, R. F. and Proulx, G., "A Study of Occupant Behavior During the World Trade Center Evacuation", Proceedings of the Seventh International Fire Science and Engineering Conference, Interflam '96, InterScience Communication, London ,UK, pp. 793-802, 1996.

10. Proulx, G., Laroche, C. and Latour, J.C., "Audibility Problems with Fire Alarms in Apartment Buildings", Proceeding of the Human Factors and Ergonomics Society 39th Annual Meeting, Vol. 2, Human Factors and Ergonomics Society, Santa Monica, CA, USA, pp. 989-993, 1995.

11. Proulx, G., "The Time Delay to Start Evacuating Upon Hearing a Fire Alarm", Proceedings of the Human Factors and Ergonomics Society 38th Annual Meeting, Vol. 2, Human Factors and Ergonomics Society, Santa Monica, CA, USA, pp. 811-815, 1994.

12. Proulx, G., "A Stress Model About People Facing a Fire", Journal of Environmental Psychology, 13, 137-147, 1993. 
13. Donald, I. and Canter, D. "Behavioural Aspects of the King's Cross Disaster", Fires \& Human Behaviour, Second Edition, D. Canter (Ed.), David Fulton Publishers, London, UK, pp. 15-30, 1990.

14. Proulx, G. and Sime, J. D., "To Prevent 'Panic' in an Underground Emergency: Why Not Tell People the Truth?", Fire Safety Science Proceedings of the Third International

Symposium, G. Cox \& B. Langford (Eds), Elsevier Applied Science, London, UK, pp. 843-852, 1991. 